\title{
Factors preceding CRM readiness in small- and medium-sized tourism enterprises
}

\author{
Authors: \\ Dinesh Vallabh \\ Laetitia Radder ${ }^{2}$ \\ Danie Venter ${ }^{3}$ \\ Affiliations: \\ ${ }^{1}$ Faculty of Business Sciences, \\ Walter Sisulu University, \\ South Africa \\ ${ }^{2}$ Department of Marketing \\ Management, Nelson \\ Mandela Metropolitan \\ University, South Africa \\ ${ }^{3}$ Unit for Statistical \\ Consultation, Nelson \\ Mandela Metropolitan \\ University, South Africa

\section{Correspondence to:} \\ Dinesh Vallabh

\section{Email:} \\ dvallabh@wsu.ac.za

\section{Postal address:} \\ Walter Sisulu University, 88 \\ Buffalo Street, East London \\ 5201, South Africa \\ Dates: \\ Received: 03 Apr. 2014 \\ Accepted: 10 Feb. 2015 \\ Published: 08 July 2015 \\ How to cite this article: \\ Vallabh, D., Radder, L. \& \\ Venter, D., 2015, 'Factors \\ preceding CRM readiness \\ in small- and medium-sized \\ tourism enterprises', Acta \\ Commercii 15(1), Art. \#263, \\ 9 pages. http://dx.doi. \\ org/10.4102/ac.v15i1.263

\section{Copyright:} \\ C 2015. The Authors. \\ Licensee: AOSIS \\ OpenJournals. This work is \\ licensed under the Creative \\ Commons Attribution \\ License.
}

Orientation: Customer relationship management (CRM) is important to organisations striving for competitive advantage through building relationships with their customers.

Research purpose: This study identified the factors preceding CRM and assessed selected South African small- and medium-sized tourism enterprises' (SMTEs) readiness for CRM.

Motivation: CRM is likely to enhance SMTEs' competitiveness. However, successful adoption and implementation of CRM is unlikely unless the organisation is ready for it.

Research design, approach and method: A quantitative research approach and survey questionnaire yielded primary data from 332 respondent organisations selected by systematic sampling. Exploratory factor analysis was used to identify the latent factors preceding CRM readiness. Organisational CRM readiness was assessed based on CRM maturity in terms of data collection, use and sharing throughout the organisation.

Main findings: Respondent-organisations performed well on the four factors preceding CRM readiness - business strategy, customer strategy, touch points and competencies, skills and technology and also on data collections and use, but not on data sharing.

Practical/Managerial implications: CRM practice is believed to assist organisations in tailoring products and services to customers' needs, providing customer satisfaction, enhancing customer retention and ultimately improving the organisation's competitiveness and profitability. CRM might fail if SMTEs do not have CRM-enabling conditions in place and a CRM readiness audit should therefore be performed.

Contribution: The study contributes to a largely under-researched area concerning CRM in SMTEs by providing an improved understanding of the factors that will enable SMTEs to engage in CRM activities.

\section{Introduction}

In South Africa, tourism is widely acknowledged as a strategic priority for achieving economic growth, particularly within the milieu of small- and medium-sized enterprises (SMEs) (Tassiopoulos 2011). However, these enterprises often do not meet expectations. This might be because of fluctuating and seasonal demand (Van Schalkwyk 2006) and problems typically faced by many SMEs. These problems are often associated with managerial competence and experience, support structures, focused strategies and organisational characteristics that limit growth (Nieman \& Nieuwenhuizen 2009; Tassiopoulos 2011; Van Aardt et al. 2008). To survive and grow despite these challenges, SMEs must find and use creative techniques and powerful strategies as a source of competitive advantage (Yilmaz 2008). Customer relationship management (CRM) might be such a strategy, as it is heralded as one of the most important means of establishing a competitive advantage in the modern business environment characterised by globalisation, increasing competition and decreasing customer loyalty (Özgener \& İraz 2006), both within a tourism context (Eid \& El-Gohary 2014) and also in the case of small- and medium-sized tourism organisations (SMTEs) (Özgener \& İraz 2006).

Organisations pursue a CRM strategy for increasing business performance and value (MiriNargesi et al. 2011). However, many organisations, in particular SMEs, are unprepared for CRM and find its application challenging (Nguyen, Newby \& Waring 2012). Attempts to implement CRM before the organisation is ready could result in unnecessary business disruption, creating unused technology capacity and could ultimately cause its implementation to fail (Miri-Nargesi et al. 2011). We therefore argue that examining the organisation's situation with regard to the factors preceding CRM engagement might help prevent these negative consequences.

Whilst a number of studies investigated the implementation of CRM, very little effort has been made to determine organisational readiness at the CRM pre-implementation stage (Miri-Nargesi 
et al. 2011). This also appears to be the case in the South African context. Past research into CRM focused mainly on financial services, banking services, knowledge management, customer strategies and customer loyalty (e.g. Berndt, Herbst \& Roux 2005; Cloete, Courtney \& Fintz 2002; Du Plessis 2010; Roberts-Lombard 2009; Roberts-Lombard, Strachan \& Du Plessis 2013; Rootman, Tait \& Sharp 2013), but did not investigate SME readiness in a tourism context. Our research aimed to help fill this void by identifying and assessing the factors preceding CRM readiness and determining the readiness of a sample of South African SMTEs.

The remainder of the article is structured as follows. Firstly, the nature of CRM, organisational CRM readiness and the factors preceding CRM are considered. Thereafter, the research methodology is explained with a focus on the research instrument, sampling and data collection and the data analysis process. Next, an analysis and an interpretation of the results are given, followed by the discussion of the results and their practical implications. A few concluding remarks follow a short section on the limitations of the study and suggestions for further research.

\section{Customer relationship management}

No uniform definition or conceptualisation of CRM seems to exist. For example, following an extensive literature review, Zablah, Bellenger and Johnston (2004) concluded that CRM is conceptualised in five ways. Firstly, CRM is a strategy that differentiates customers based on their loyalty and profitability. Secondly, CRM is defined as a technological instrument for collecting, storing, analysing and disseminating customer knowledge. Such knowledge increases the organisation's ability to respond to individual customers' needs. In a third conceptualisation, CRM is referred to as a capability that represents the mix between customer knowledge and the skills to develop and manage customer relationships. CRM is furthermore seen as a process of building and managing interactions and profitable and beneficial long-term relationships with customers. Lastly, CRM is a philosophy focused on customer relationship initiating, maintaining and enhancing.

Vallabh (2014) also performed an extensive review of the literature on CRM. Following his analysis of 42 journal articles published between 2001 and 2014, he concludes that CRM is defined from three perspectives similar to those suggested by Payne and Frow (2005). Firstly, CRM is defined narrowly and tactically as a particular technology solution that helps improve targeting efforts by extending separate databases and sales force automation tools to bridge sales and marketing functions (Chen \& Popovich 2003). The second perspective regards CRM as a sophisticated technology application that provides an interface between customers and a variety of touch points such as the organisation's salespeople, service personnel, call centres and internet websites (Parvatiyar \& Sheth 2001). The application of CRM implies that the organisation 'collect and analyse data on customer patterns, interpret customer behaviour, develop predictive models, respond with timely and effective customised communications, and deliver product and service value to individual customers' (Chen \& Popovich 2003). The third perspective of CRM is that it should be defined both broadly and strategically. According to this view, CRM is a cross-functional integration of processes, people, operations and marketing capabilities enabled through information, technology and applications (Payne \& Frow 2005). It is aimed at creating value for targeted customers at a profit (Iriana \& Buttle 2006) through the alignment of business and customer strategy (Parvatiyar \& Sheth 2001; Payne \& Frow 2005). A business strategy should start with the organisation's mission, vision and objectives, an analysis of its culture in terms of organisational policy and values and an analysis of the environment (Chalmeta 2006). A customer strategy requires identifying relevant customers, analysing their profitability and setting customer objectives per segment and per individual customer. The value creation process is embedded in determining what value the organisation can provide customers and receive from customers and in managing this exchange (Payne \& Frow 2005).

CRM can therefore be conceptualised as a managerial philosophy that seeks to build long-term relationships with customers (Berndt et al. 2005) through the strategic application of people, processes and technology (Özgener \& İraz 2006) in an integrated manner (Chen \& Popovich 2003). It is focused on 'building a learning customer relationship, developing a base of loyal customers and at the same time increasing profitability' (Berndt \& Tait 2013). The dialogue and learning relationship with customers, products and services can enhance the customisation of products and services to better meet customers' needs (Buhalis 2003) and to deliver value to customers in a better manner than the competitors. CRM therefore increases the ability of the organisation to gain, retain and satisfy customers both efficiently and effectively (Eid \& El-Gohary 2014). Customer satisfaction is important because satisfied customers are likely to return and recommend the organisation's product or service to others; this contributes to sustaining the positive relationship between customer satisfaction and organisational profits (Roberts-Lombard et al. 2013). Given these benefits, CRM might therefore serve as a strategy to increase competitiveness and help more SMTEs make a contribution to South Africa's economic growth.

\section{Organisational readiness for customer relationship management}

Ocker and Mudambi (2003) argue that before organisations invest scarce resources in a risky technology innovation such as CRM, the organisation's readiness to compete based on CRM should be examined. Following a similar argument, Duțu and Hălmăjan (2011) hold that the goal of measuring organisational readiness for CRM is to assess the degree to which the organisation is prepared for CRM adoption relative to competitors. Croteau and $\mathrm{Li}$ (2003) define organisational readiness for CRM as the level of technological resources available to an organisation, whilst Duțu and Hălmăjan (2011) 
and Racherla and $\mathrm{Hu}$ (2008) point out that organisational readiness is related to the level of available technological resources that may support CRM adoption. It is thus evident that technological resources play an important role in organisational CRM readiness.

According to Santoso (2008), four components are necessary for CRM adoption - relationship marketing, an appropriate organisational structure, leveraging of the data warehouse and data mining and data utilisation for customer management. Relationship marketing, which can be regarded as strategic factors, on the one hand concerns a strong emphasis on building long-term relationships with customers and, on the other, focuses on the recognition of information technology's (IT's) role as a tool to achieve this goal. An appropriate organisational structure, the second component, refers to competent employees with sufficient knowledge of IT, technology and marketing. Since IT personnel typically possess rich knowledge about IT and technology, but lack marketing knowledge, Santoso (2008) strongly recommends establishing cross-functional interaction between IT and marketing. The third dimension concerns the leveraging of the data warehouse and data mining. Organisations thus need appropriate data mining tools to identify similar customer behaviour or profiles and explore patterns and relationships between variables. The fourth important aspect is data utilisation for customer management. The data warehouse should be used to identify and prioritise customers and target segment determination, that is, data utilisation for the purpose of customer management (Santoso 2008).

Another approach to assessing CRM readiness (containing many of the components also listed by Santoso [2008]) is the one proposed by Payne (2006). He argues that an assessment should first be made of overall CRM maturity as this will provide a general perspective on the organisation's current situation. Five levels of CRM maturity can be differentiated based on the organisation's ability to integrate and use data to build profitable customer relationships and the specific activities undertaken in implementing CRM projects. In the first stage, Pre-CRM planning, organisations recognise the importance of CRM activities, but have not yet progressed beyond this stage. Payne (2006) suggests that organisations that find themselves in this stage and consider introducing CRM, should undertake a CRM readiness audit. The second stage, Building a data repository, relates to building the data warehouse, that is, collecting and evaluating existing data, updating customer records and verifying data integrity. In stage 3, Moderately developed CRM, the focus shifts toward data mining and determining the value that can be extracted from the organisation's existing customer information. Stage 4, Well-developed CRM, is characterised by the use of electronic commerce applications, a clear understanding of profitable customers and how to retain them, as well as a focus on customer segmentation and profiling. In the final stage, Highly-developed CRM, extensive data warehouse access is offered within the organisation, advanced techniques and data visualisation tools are used to present the data and ongoing dialogue with customers is prevalent. The importance of data management and the ability to integrate and use data to build profitable customer relationships as an indication of CRM readiness is evident in progressing from the Pre-CRM planning to the Highly-developed CRM phase.

Few models for measuring CRM readiness could be found in the literature. Of note is the three-dimensional (intellectual, social and technological) alignment model proposed by Ocker and Mudambi (2003). In this model, the intellectual dimension refers to the organisation being customer-centric and market oriented, committing resources to employee education and training and subscribing to business processes that integrate customer-related knowledge, incentives and rewards for employees. Planning and decision-making are integrated across corporate, business unit and the functional levels of marketing, sales, customer service, accounting, purchasing, production and logistics. The social dimension entails a culture of shared values and behaviour, a positive attitude toward technology and employee empowerment, domain knowledge within and across units and a willingness to share knowledge. High-quality customer information is shared so that a rich customer knowledge repository is maintained and made available to all employees. The technology dimension includes data warehousing supported by data structures, standards and models to facilitate the requisite organisation of data in the knowledge repository. Whilst the Ocker and Mudambi (2003) model might not be readily applicable to SMEs, the role of technology in collecting, using and sharing customer data is once more evident.

\section{Factors with an impact on customer relationship management and its adoption}

Despite the benefits CRM holds for the organisation and the customer, the literature (e.g. Miri-Nargesi et al. 2011) reports a high failure rate for CRM amongst large and small organisations, seemingly resulting from a myriad challenges, conditions and circumstances. As was the case with CRM readiness, it can be argued that if SMEs cannot effectively handle the challenges, or do not have the CRM-enabling conditions in place, it is unlikely that they will successfully adopt CRM.

In addition to the elements of CRM readiness discussed in the previous section, a number of challenges specific to SMEs' engagement with CRM have been identified in the literature. Some of these overlap with the factors associated with CRM readiness discussed in the previous section and with the problems generally faced by SMEs. Factors to be dealt with include top management's support and commitment (Brink \& Berndt 2010; Ocker \& Mudambi 2003; Prasongsukarn 2006), a customer-management orientation, integration and alignment of organisational processes (Kumar \& Reinartz 2006) and knowledge management (Stefanou, Sarmaniotis \& Stafyla 2003). Alshawi, Missi and Irani (2011) list the following factors relevant to SMEs - coping with and managing complex data quality issues; staff and managerial IT skills; organisation size; strategy and business objectives; IT infrastructure and integration; and customer data 


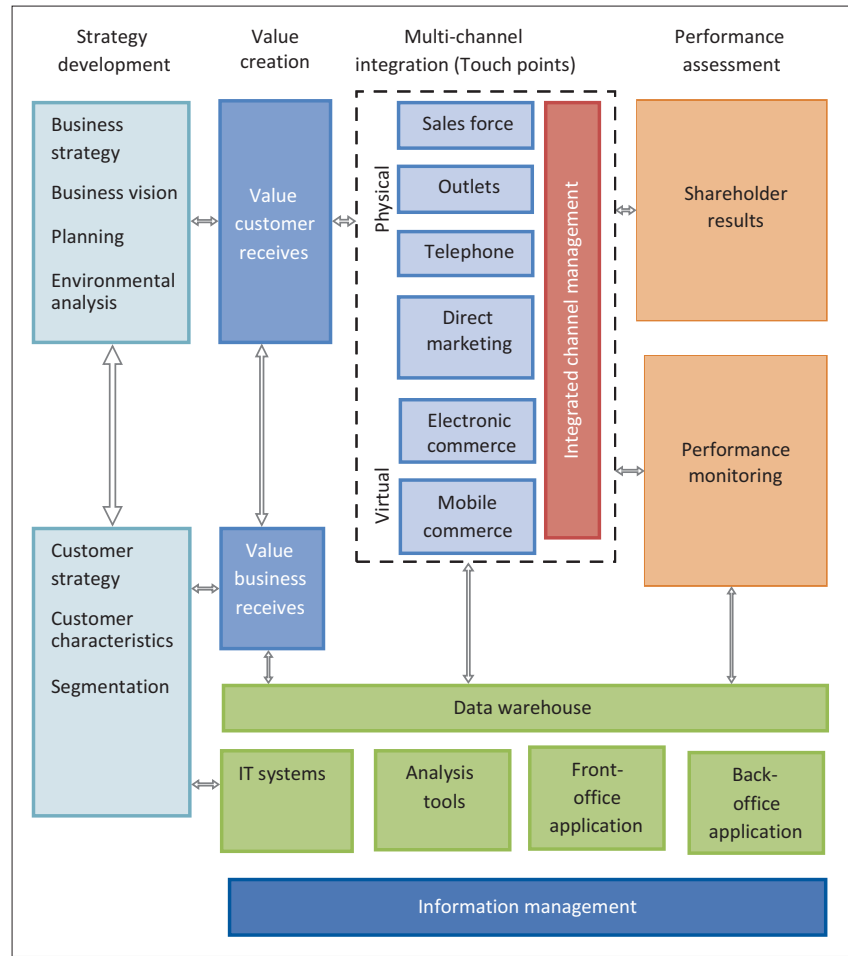

Source: Payne, A. \& Frow, P., 2005, 'A strategic framework for customer relationship management', Journal of Marketing 69, 167-176

FIGURE 1: Processes forming part of customer relationship management.

infrastructure, quality and classification. Nguyen and Waring (2013) add organisational characteristics (size and staff involvement) and management characteristics (age, gender, education and innovativeness). Important factors suggested by Lin, Guo and Lee (2006) include maturity of information technologies, competition status for the enterprise, CRM system provider's expertise, innovation acceptance ability and type of industry. Ko et al. (2008) highlight similar factors: firm size, organisational strategy, maturity of the information system, the product category, seasonality and the age of the chief executive officer, whilst Kuada and Serles (2006) list customer orientation, size, line of business and age of the SME organisation.

\section{Factors preceding customer relationship management readiness}

When those factors with an impact on CRM and those affecting CRM readiness are compared, some overlap is evident. For purposes of the empirical study, we therefore suggest that factors preceding CRM readiness should be approached from a strategic and cross-functional perspective (Figure 1). We support Payne's (2006) view that such an approach should be based on five key processes, namely, strategy development, value creation, multi-channel integration, information management and performance assessment. Since our research focused particularly on factors preceding CRM readiness, little emphasis was placed on the performance assessment management process. The strategy development process comprises a business strategy to deal with where the organisation is and what it wants to achieve, along with a customer strategy concerning the question, 'Who are the organisation's customers and how should they be segmented?' With regard to the value creation process, the organisation should know how value is delivered to customers and how their lifetime value is maximised. Multi-channel integration requires that the organisation makes decisions on how to reach its customers and how the customers can reach the organisation, as well as on delivering a positive customer experience at an affordable cost. The information management process refers to the way information on customers is organised and used to improve relationships. Performance assessment focuses on profits and shareholder value, setting of standards, developing of metrics and measuring of results and performance (Payne 2006).

\section{Research method and design}

This section discusses the questionnaire as research instrument, sampling and data collection processes, and the analysis of the data.

\section{Research instrument}

A comprehensive self-administered questionnaire, of which three sections are relevant to this article, served as the data collection instrument. One section comprised 40 items intended to measure factors preceding CRM. Twenty-four of the items were adapted from Payne (2006), two were adapted from Croteau and $\mathrm{Li}$ (2003) and 14 were generated by the researchers based on a variety of other literature studied. Respondents had to indicate their level of agreement with these items on a five-point semantic differential scale with 'strongly disagree' and 'strongly agree' as end points. A further section intended to assess CRM readiness. Given the prominence of data management in the literature as representing organisational CRM readiness, and the notion that the level of readiness is reflected in the use of data to enhance customer relationships, the CRM maturity assessment suggested by Payne (2006) was chosen as the basis for assessing CRM readiness of the respondent organisations. Fifteen items were divided into three categories, namely, data collection, data usage and data sharing. Each category comprised five options scored from 0 to 4 , where 0 denoted the lowest and 4 the highest level of maturity. The last section of the questionnaire used predominantly closed questions to source details which would allow the profiling of managers and their organisations. The questionnaire was preceded by a cover letter that explained the research's purpose, assured anonymity of participants and provided instructions for its completion.

After its construction the questionnaire was scrutinised by two senior academics with relevant experience in small business and CRM and tested in two pilot studies: the first in the form of structured interviews with three owners of small tourism businesses and the second with 32 respondents. These pilot studies contributed to the further refinement of the questionnaire.

\section{Sampling and data collection}

The data were collected from managers and owners of SMTEs located in the Eastern Cape Province of South Africa. This 
province was chosen for practical reasons and also because it is one of the provinces characterised by low economic growth and high levels of poverty and unemployment. These factors impact negatively on the sustainability of SMTEs in the area (Vallabh \& Radder 2010) and ways have to be found to help these organisations survive and grow. Although there is no reason to believe that the results of a similar study into SMTEs elsewhere in South Africa will differ significantly (but this would need to be established), the expected benefits arising from the adoption and successful implementation of CRM might help improve the competitiveness of these organisations and their contribution to the region's economy.

The Eastern Cape Parks and Tourism Agency database, comprising about 2300 registered tourism businesses, served as the study population. These businesses mostly include bed and breakfast establishments (B\&Bs), restaurants, transport services, coffee shops, travel agencies and guest houses. However, there is a predominance of accommodation establishments which resulted in the majority of the respondents being owners of B\&Bs and guest houses. Since the population was segregated into mutually-exclusive sub-populations, it was possible to use systematic random sampling. In total, 332 respondents were selected from the list and, after using on-line, face-to-face and a telephone survey and numerous follow-ups, 310 useable questionnaires were completed. Respondents whose organisations did not meet the criteria for SMEs with a maximum of 200 employees (Mahembe 2011) were omitted from the analysis.

\section{Data analysis}

The data were analysed using IBM SPSS for Windows software, version 20.0 (IBM Corp., Armonk, NY 2011). Firstly, descriptive statistics such as frequency distributions, mean scores and standard deviations were generated. Thereafter, the factorability of the data (factors preceding CRM readiness) was assessed. Since the Kaiser-Meyer-Olkin (KMO) measure of sampling adequacy (Kaiser 1970) was 0.932 (exceeding the threshold value of 0.70 ) and the Bartlett's test of sphericity (Bartlett 1954) was significant $(p<0.001)$, the data were regarded as suitable for factor analysis.

Cattell's scree test (Cattell 1966) was used to determine the number of factors. A clear elbow appeared after the fourth factor indicating the existence of four latent factors. Since all four factors made logical sense in the context of the literature, these factors were retained. Six items were deleted because of loadings below 0.35 , or not fitting the factor where it was supposed to load. The Cronbach's alpha coefficients ranged from 0.81 to 0.88 , which exceeded the threshold value of 0.70 for adequate internal consistency (Pallant 2013).

\section{Results}

\section{Profile of the respondents and their organisations}

The respondents were located in six districts, namely, Amathole (35\%), Cacadu (23\%), Chris Hani $(11 \%)$, OR
Tambo (6\%), Ukhahlamba (6\%) and Alfred Nzo (1\%), as well as two metropolitan areas, namely, Nelson Mandela Metro (10\%) and Buffalo City Metro (7\%). Only 11\% of the organisations had been in existence for 2 years or less, $22 \%$ had been operating for 3-4 years, 31\% for 5-9 years, and 36\% for 10 years and more. Forty-three per cent were sole traders, $69 \%$ had a gross annual turnover of below R500 000, 18.3\% had an annual turnover of R500 000 - R999 999 and 12.7\% managed a turnover of Rl million and more. Just below half of the respondent organisations (47.4\%) had four and fewer full-time employees, $29 \%$ employed five to nine people on a full-time basis and $22 \%$ employed 10 or more people.

The majority $(67 \%)$ of the managers were between 35 and 54 years old, $24.5 \%$ had a matric qualification or lower, whilst $10.2 \%$ had a postgraduate qualification. The largest group ( $42 \%$ ) of respondents were trained and experienced $(62.6 \%)$ in General Management, whilst almost a third had no training or experience in Financial Management, Human Resources Management, Strategic Management or Project Management.

\section{Factors preceding organisations' readiness for customer relationship management}

As mentioned, four factors resulted from the factor analysis (Table 1). Factor 1, Business strategy, gathered nine items describing activities related to the organisation's vision, objectives, environmental analysis and business plans. Factor 2, Customer strategy, grouped together activities related to interacting and building relationships with customers. More than $73 \%$ of the respondents engage positively in each of these activities reflecting aspects of customer strategy. Factor 3, Touch points, describes the respondent organisations' communication channels or points of interaction with their customers. More than $70 \%$ of the organisations use modern technology to interact with their customers and $67 \%$ use social media for this purpose. The last factor, namely, Factor 4, Competencies, skills and technology, describes technical resources and the availability of skills in handling technology. All item mean scores in this factor were equal to or greater than 4.00 on the five-point response scale used in the survey for this study.

Overall, a large percentage of the respondents (Table 1) agreed with the statements. A comparison of the factor mean scores showed that respondents were most positive about Competencies, skills and technology and least positive about Touch points being present in the business.

Upon comparing the respondent organisations' performance on the factors preceding CRM readiness relative to the ideal position (Figure 2), it is clear that, overall, the respondent SMTEs are in a good position, with the best position relative to the ideal being that of Competencies, skills and technology and the worst being that of Touch points.

\section{Organisational readiness for customer relationship management}

As explained under Research method and design, Payne's (2006) suggestion was used to assess organisational CRM 
TABLE 1: Descriptive statistics and results of factor analysis.

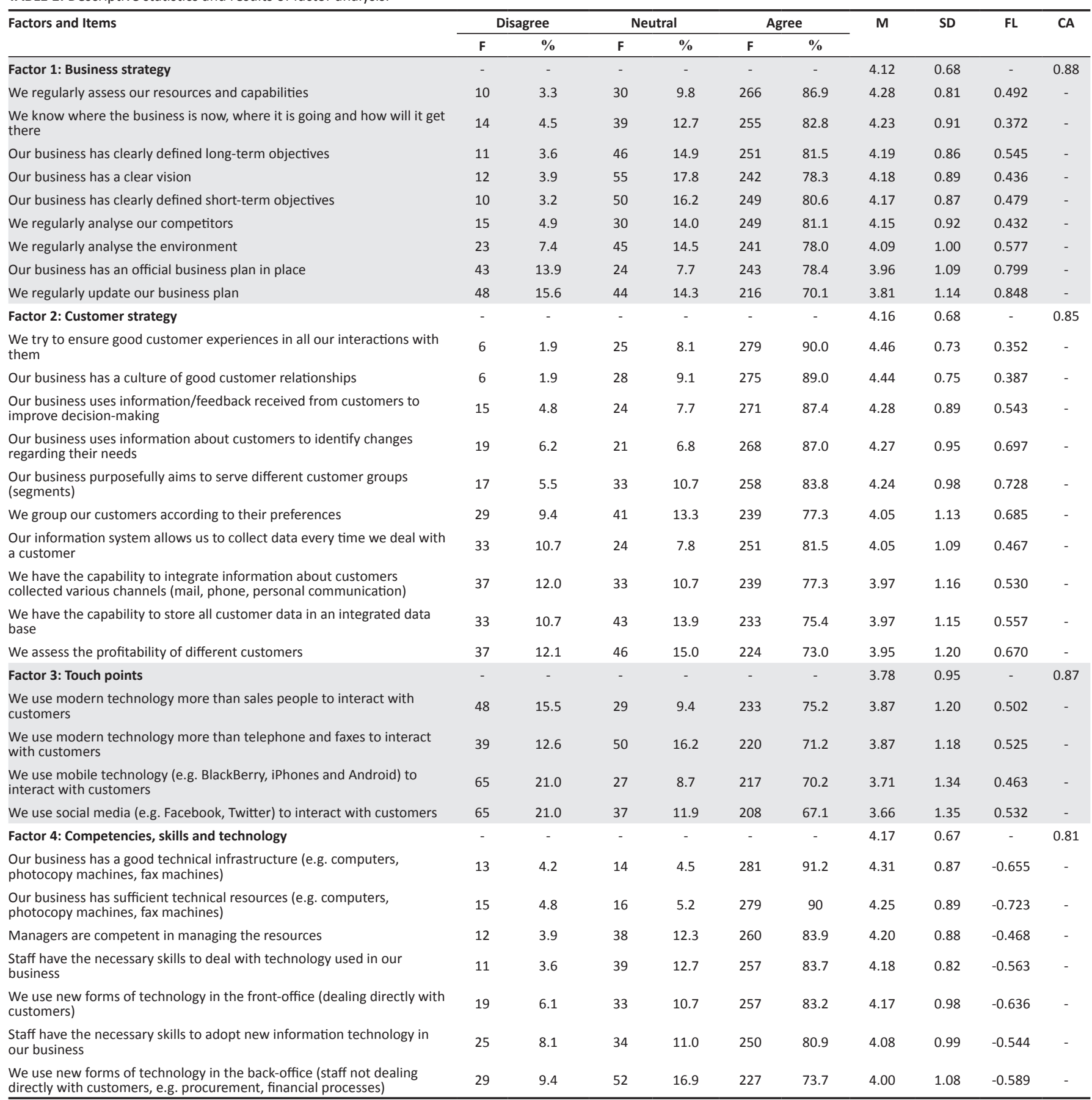

F, Frequency; M, Mean score; SD, Standard deviation; FL, Factor loading; CA, Cronbach's alpha.

readiness (Table 2 ). As many as $17.2 \%$ of the respondents had a zero level of CRM readiness with respect to Data collection, whilst less than 5\% reached level 4 (Highly advanced). Almost equal percentages of respondents were in levels 1, 2 and 3 of CRM readiness. A more-or-less similar pattern is reflected in the case of Data usage. A large proportion of the respondent organisations (44.1\%) scored very low on Data sharing and only $6.6 \%$ had reached level 4 .

\section{Ethical considerations}

This article is based on research conducted in accordance with the relevant Nelson Mandela Metropolitan University
(NMMU) guidelines for ethical research. The research did not include the involvement of animals, any vulnerable persons or groups, participants from institutions such as hospitals, schools or prisons. It met all the requirements for completion of the pro forma ethics application, and hence full ethics from the NMMU Research Ethics Committee: Human was not required. For this reason, no ethics permit number is available.

\section{Potential benefits and hazards}

No respondent in this study entailed any risk based on his or her participation, or will be harmed or benefit as a result 


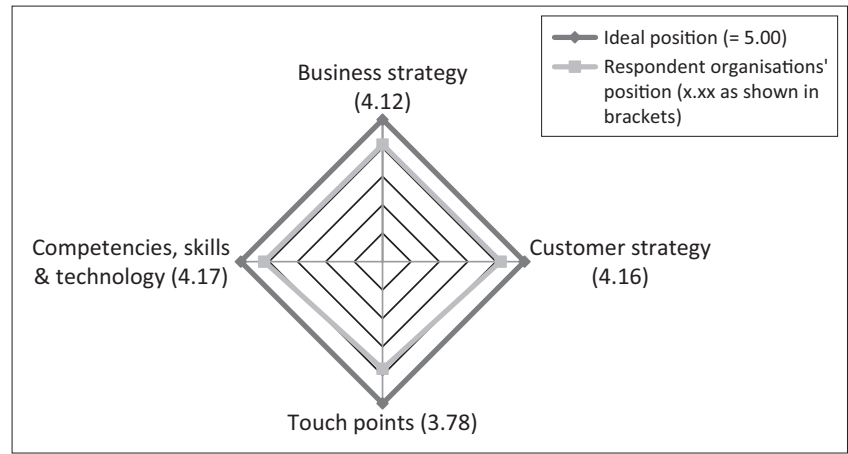

FIGURE 2: Level of factors preceding readiness for customer relationship management within respondent organisations.

TABLE 2: Frequency distribution of responses to items measuring customer relationship management readiness.

\begin{tabular}{|c|c|c|c|}
\hline \multirow[t]{2}{*}{ Data } & \multirow{2}{*}{$\begin{array}{l}\text { Readiness } \\
\text { level }\end{array}$} & \multicolumn{2}{|c|}{ Variable } \\
\hline & & $\mathbf{F}$ & $\%$ \\
\hline \multicolumn{4}{|l|}{ Data collection $(n=309)$} \\
\hline We do not collect data about our customers & 0 & 53 & 17.2 \\
\hline We collect only some data about our customers & 1 & 83 & 26.8 \\
\hline We collect extensive data about our customers & 2 & 72 & 23.3 \\
\hline $\begin{array}{l}\text { We use the extensive data about our customers } \\
\text { to build a profile of each }\end{array}$ & 3 & 86 & 27.8 \\
\hline $\begin{array}{l}\text { The profiles of our customers are integrated in } \\
\text { an electronic database }\end{array}$ & 4 & 15 & 4.9 \\
\hline \multicolumn{4}{|l|}{ Data usage $(n=307)$} \\
\hline We never use data about our customers & 0 & 59 & 19.2 \\
\hline $\begin{array}{l}\text { We occasionally use the data we have collected } \\
\text { about our customers }\end{array}$ & 1 & 77 & 25.1 \\
\hline $\begin{array}{l}\text { We use data about our customers to classify them } \\
\text { into different groups }\end{array}$ & 2 & 62 & 20.2 \\
\hline $\begin{array}{l}\text { We are able to tell who our most profitable } \\
\text { customers are }\end{array}$ & 3 & 77 & 25.1 \\
\hline $\begin{array}{l}\text { We manage our customers in order to maximise the } \\
\text { value we derive from our interactions with them }\end{array}$ & 4 & 32 & 10.4 \\
\hline \multicolumn{4}{|l|}{ Data sharing $(n=306)$} \\
\hline Data about customers are not shared amongst staff & 0 & 135 & 44.1 \\
\hline A few staff members share some data about customers & 1 & 56 & 18.3 \\
\hline $\begin{array}{l}\text { Data about customers are often shared amongst } \\
\text { staff members }\end{array}$ & 2 & 30 & 9.8 \\
\hline $\begin{array}{l}\text { Data about customers are shared amongst most } \\
\text { staff members }\end{array}$ & 3 & 65 & 21.2 \\
\hline $\begin{array}{l}\text { All data about customers are shared amongst all } \\
\text { staff (back-office and front-office) }\end{array}$ & 4 & 20 & 6.6 \\
\hline
\end{tabular}

F, Frequency.

of his or her participation. No participant is identified in any way and only aggregate results have been shown.

\section{Recruitment procedures}

Respondents' participation in the study was totally voluntarily and any participant could withdraw from the study at any time.

\section{Informed consent}

Since participation was totally voluntarily, no informed consent was required. Consent was given by virtue of the respondent's completion of the questionnaire.

\section{Data protection}

Data were captured electronically and are stored electronically on the password-protected work computers in the offices of the researchers. No electronic or hard copies of the data have or will be made available to any person, group or organisation.

\section{Trustworthiness}

The researchers reported the findings in a complete and honest fashion, without misrepresenting what was done or intentionally misleading others about the nature of the findings.

\section{Validity and reliability External validity}

The sample of respondents was drawn from the Eastern Cape Parks and Tourism Agency's database. The majority of the SMTEs on the list were accommodation establishments and the results of the study can therefore not be generalised to all SMTEs in South Africa.

\section{Face validity}

To ensure that the measure reflects the content of the concepts in question, relevant literature, previous research and experts in the field were consulted.

\section{Internal validity}

The research was of a descriptive nature and no causal relationships were determined.

\section{Reliability}

Cronbach coefficient alphas ranged from 0.81 to 0.88 , which exceeded the threshold value of 0.70 .

\section{Discussion Outline of the results}

To survive in the global market, focusing on the customer is becoming a key factor for SMEs (Özgener \& İraz 2006) and is regarded as a 'very important tool to increase any organization's ability to gain, retain, and satisfy customers both efficiently and effectively through creating and sustaining good, long-lasting relationships with customers' (Eid \& El-Gohary 2014). CRM is thus considered an important means of establishing competitive advantage (Eid \& El-Gohary 2014) and a path to increased competitiveness, higher revenues and lower operational costs (Chen \& Popovich 2002). However, many CRM projects fail (Miri-Nargesi et al. 2011). Failure may also be a result of organisations attempting to implement CRM before they are ready to do so. In fact, the success of a CRM programme depends very much on a sufficient level of preparedness within the organisation (Payne 2006). It is, therefore, important to assess the current situation of the organisation (Miri-Nargesi et al. 2011). The aim of this study was to identify and determine the presence of factors preceding CRM readiness in a sample of South African SMTEs and to assess their level of CRM readiness.

Four factors preceding organisational CRM, namely, business strategy, customer strategy, touch points and competencies, 
skills and technology, resulted from the exploratory factor analysis. The results confirmed that all of these factors are present in the surveyed organisations. They reported to have the Competencies, skills and technology required for CRM and to engage in the activities associated with Business and Customer strategies, but seem to experience challenges with respect to Touch Points, that is, integrating conventional and virtual points of interaction with the customer across presales communications, sales interactions, post-sales service and support and using these in value-adding interactions with customers.

Following the argument by Payne (2006), we also assessed organisational CRM readiness by determining respondentorganisations' level of CRM maturity. The results showed that with regard to data collection, the largest group of respondents fell into level 3 (Moderately developed), which means that they collect extensive data about their customers which is used to build customer profiles, but these profiles are not yet integrated into an electronic database useable by all in the organisation. The latter is achieved by less than $5 \%$ of the respondent SMTEs. The second indication of organisational CRM readiness concerns the data usage. Overall, more organisations fell into the lower levels of readiness. As many as $19.2 \%$ of the organisations never use the data collected about their customers, whilst $25.1 \%$ occasionally use the data. Only $25.1 \%$ was able to tell who their most profitable customers were and only $10.4 \%$ managed their customers aimed at maximising the value derived from them. The most advanced indicator of CRM readiness is the sharing of data in the organisation. Whilst a mere $6.6 \%$ of the organisations reported sharing customer data between front- and backoffice staff, as many as $44.1 \%$ did not share data at all and can thus be classified as being in the Pre-CRM level of readiness

\section{Practical implications}

Tourism is widely acknowledged as a vehicle for economic growth, particularly within the milieu of the small business sector and SMTEs have to cope with fluctuating and seasonal demand in addition to the typical problems associated with small businesses. These organisations must find ways to survive and grow, despite these challenges. Building longterm relationships with customers through an integrated application of people, processes and technology can help organisations customise their products and services to better meet customers' needs and ensure their satisfaction. However, certain factors need to be in place before SMTEs can effectively implement CRM and these organisations should exhibit an advanced level of organisational readiness.

The findings from this study extend the understanding of CRM readiness in SMTEs and the factors that should be in place prior to an organisation engaging in such a costly technological innovation. The research furthermore provided a framework for assessing organisational CRM readiness. This framework can easily be used by SMTEs and other organisations as an aid in identifying their level of data management and CRM maturity. The results on CRM readiness also contributed to a better understanding of the participant SMTEs by highlighting that whilst the required factors are mostly in place, the organisations fail to make proper use of the customer data they collect.

Specific managerial implications of the study relate to two inter-related activities, namely, the lack of efficient and effective use of Touch points and the lack of data sharing throughout the organisation. To improve their ability to effectively deal with Touch points, SMTE management have to purposefully select and integrate the most appropriate combination of channel options through which to interact with their customers. Part of this interaction is the collection of data which should be shared throughout the organisation This will enhance the cross-functional integration of people, processes, operation and marketing capabilities and help create value aimed at targeted customers. Since the respondents reported that they possess a high level of technology and IT capabilities, such data sharing and integration should be possible. The lack of data sharing throughout the organisation is likely to considerably negate the advantages of obtaining appropriate customer information and building learning relationships with customers.

\section{Limitations of the study}

The limitations of the study inevitably suggest opportunities for further research. Firstly, the results cannot be generalised and have to be interpreted with caution because all of the respondent organisations were located in the Eastern Cape Province and the majority were accommodation establishments. Future research should be conducted amongst SMTEs in other parts of the country and amongst SMEs outside the tourism industry before results can be generalised. Secondly, CRM readiness was assessed using one approach only, namely, that of the approach of data management. The impact of organisational and managerial characteristics on organisational CRM readiness and other measures of readiness might be worth investigating.

\section{Conclusion}

This study delineated four important factors preceding CRM readiness. Relative to the ideal position, SMTEs in the Eastern Cape are doing fairly well with respect to competencies, skills and technology; customer strategy; and business strategy. They did, however, show a weaker performance in the case of using conventional and virtual technology (touch points) in interacting with their customers. This is a positive step in the direction of SMTEs preparing for CRM implementation. Unfortunately, their current readiness for CRM implementation showed less positive results. When measured against the notion of data management as an indicator of organisational readiness for CRM, less than half of the respondent-organisations have reached the more advanced levels of data collection and data usage, whilst more than $60 \%$ have only reached the lower levels for data sharing. This situation can be addressed effectively through education and training. A simulation of the framework and 
methods used in this study in assessing individual SMTEs' performance with respect to the factors preceding CRM and examining their CRM readiness provides a useful avenue for increasing an organisation's competitiveness and its contribution to South Africa's economic growth.

\section{Acknowledgements}

The authors appreciate the invaluable suggestions made by the editors and anonymous reviewers in improving the article.

\section{Competing interests}

The authors declare that they have no financial or personal relationship(s) that may have inappropriately influenced them in writing this article.

\section{Authors' contributions}

D.V. (Walter Sisulu University) conceptualised the research idea, collected the data and wrote the first article draft. L.R. (Nelson Mandela Metropolitan University) assisted in conceptualising the research and rewrote the article. D.V. (Nelson Mandela Metropolitan University) performed part of the data analysis.

\section{References}

Alshawi, S., Missi, F. \& Irani, Z., 2011, 'Organisational, technical and data quality factors in CRM adoption - SMEs perspective', Industrial Marketing Management 40(3), 376-383. http://dx.doi.org/10.1016/j.indmarman.2010.08.006

Bartlett, M.S., 1954, 'A note on the multiplying factors for various chi-square approximations', Journal of the Royal Statistical Society 16(Series B), 296-298.

Berndt, A., Herbst, F. \& Roux, L., 2005, 'Implementing a customer relationship management programme in an emerging market', Journal of Global Business and Technology 1(2), 81-89.

Berndt, A. \& Tait, M., 2013, Relationship marketing \& customer relationship management, 2nd edn., Juta Academic Publishers, Cape Town.

Brink, A. \& Berndt, A., 2010, Relationship marketing and customer relationship management, Juta Academic Publishers, Cape Town.

Buhalis, D., 2003, eTourism: Information technology for strategic tourism management, Prentice-Hall, London.

Cattell, R.B., 1966, 'The screen test for the number of factors', Multivariate Behavioral Research 1(2), 245-276. http://dx.doi.org/10.1207/s15327906mbr0102_10

Chalmeta, R., 2006, 'Methodology for customer relationship management', Journa of Systems and Software 79(7), 1015-1024. http://dx.doi.org/10.1016/j.jss. 2005.10.018

Chen, I.J. \& Popovich, K., 2003, 'Understanding customer relationship management (CRM): People, process and technology', Business Process Management Journal 9(5), 672-688. http://dx.doi.org/10.1108/14637150310496758

Chen, P.Y. \& Popovich, P.M., 2002, Correlation: Parametric and nonparametric measures, Sage Publications, Thousand Oaks, CA

Cloete, E., Courtney, S. \& Fintz, J., 2002, 'Small businesses' acceptance and adoption of e-commerce in the Western Cape Province of South Africa', The Electronic Journal on Information Systems in Developing Countries 10(4), 1-13.

Croteau, A-M. \& Li, P., 2003, 'Critical success factors of CRM technological initiatives', Canadian Journal of Administrative Sciences 20(1), 21-34. http://dx.doi.org /10.1111/j.1936-4490.2003.tb00303.x

Du Plessis, L., 2010, 'Customer relationship management and its influence on customer loyalty at Liberty Life in South Africa', Masters' dissertation, Business Management, Faculty of Management, University of Johannesburg.

Duțu, C. \& Hălmăjan, H., 2011, 'CRM processes and the impact on business performance', Proceedings of the 5th WSEAS International Conference on Economy and Management Transformation (Volume II), Romania.

Eid, R. \& El-Gohary, H., 2014, 'Testing and validating customer relationship management implementation constructs in Egyptian tourism organizations' Journal of Travel \& Tourism Marketing 31(3), 344-365. http://dx.doi.org/10.1080/ 10548408.2014.883348

Iriana, R. \& Buttle, F., 2006, 'Customer relationship management (CRM) system implementations: An assessment of organisational culture', The International Journal of Knowledge, Culture and Change Management 6(2), 137-148.
Kaiser, H.F., 1970, 'A second generation little jiffy', Psychometrika 35(4), 401-415. http://dx.doi.org/10.1007/BF02291817

Ko, E., Kim, S.H., Kim, M. \& Woo, J.Y., 2008, 'Organisational characteristics and CRM adoption process', Journal of Business Research 61(1), 65-74. http://dx.doi. org $/ 10.1016 /$ j.jbusres.2006.05.011

Kuada, J. \& Serles, D., 2006, 'Customer relationship marketing (CRM) practices in Danish small businesses', International Management Review 2(4), 28-44.

Kumar, V. \& Reinartz, W.J., 2006, Customer relationship management: A databased approach, John Wiley \& Sons, Inc., New York.

Lin, J-Y., Guo, Z-L. \& Lee, C-W., 2006, 'A panel study for the influential factors of the adoption of customer relationship management system', International Journal of Electronic Business Management 4(5), 410-418.

Mahembe, E., 2011, Literature review on small and medium enterprises' access to credit and support in South Africa, National Credit Regulator (NCR), Pretoria.

Miri-Nargesi, S.S., Keramati, A., Haleh, H. \& Ansarinejad, A., 2011, 'Assessing organizational readiness to implement customer relationship management using fuzzy analytical network process: A case study', International Journal of Academic Research 3(3), 409-418.

Nguyen, T.H., Newby, M. \& Waring, T.S., 2012, Understanding customer relationship management (CRM) technology adoption in SMEs: An empirical study in the USA, presented at the UK Academy for Information Systems 17th Annual International Conference, 27-28 March, Oxford.

Nguyen, T.H. \& Waring, T.S., 2013, 'The adoption of customer relationship management (CRM) technology in SMEs: An empirical study', Journal of Smal Business and Enterprise Development 20(4), 824-848. http://dx.doi.org/10.1108/ JSBED-01-2012-0013

Nieman, G. \& Nieuwenhuizen, C., 2009, Entrepreneurship: A South African perspective, 2nd edn., Van Schaik, Pretoria.

Ocker, R.J. \& Mudambi, S., 2003, Assessing the readiness of firms for CRM: A literature review and research model, presented at the 36 th Hawaii International Conference on System Sciences, 69 January, Big Island, HI.

Özgener, S. \& İraz, R., 2006, 'Customer relationship management in small-medium enterprises: The case of Turkish tourism industry', Tourism Management 27(6), 1356-1363. http://dx.doi.org/10.1016/j.tourman.2005.06.011

Pallant, J., 2013, SPSS survival manual, 5th edn., Open University Press, McGraw Hill Education, Berkshire.

Parvatiyar, A. \& Sheth, J.N., 2001, 'Customer relationship management: Emerging practice, process, and discipline', Journal of Economic and Social Research 3(2), 1-34.

Payne, A., 2006, Handbook of CRM: Achieving excellence in customer management, Butterworth-Heinemann, Oxford. http://dx.doi.org/10.1509/jmkg.2005.69.4.167

Payne, A. \& Frow, P., 2005, 'A strategic framework for customer relationship management', Journal of Marketing 69, 167-176.

Prasongsukarn, K., 2006, Customer relationship management from theory to practice: Implementation steps, Inspire Research Company, Thailand.

Racherla, P. \& Hu, C., 2008, 'eCRM system adoption by hospitality organizations: A technology-organization-environment (TOE) framework', Journal of Hospitality \& teisure Marketing 17(1-2), 30-58. http://dx.doi.org/10.1080/10507050801978372

Roberts-Lombard, M., 2009, 'Customer retention strategies implemented by fastfood outlets in the Gauteng. Western Cape and Kwazulu Natal Provinces of South Africa: A focus on Something Fishy, Nandos and Steers', African Journal of Marketing Management 1(2), 70-80.

Roberts-Lombard, M., Strachan, L. \& Du Plessis, L., 2013, 'The influence of trust, commitment and conflict-handling on customer loyalty: A parallel investigation', Journal of Economic and Financial Sciences 6(1), 195-216.

Rootman, C., Tait, M. \& Sharp, G., 2013, 'The influence of demographic variables on relationship banking: An international study', Global Business and Economics Review 5(2-3), 133-147. http://dx.doi.org/10.1504/GBER.2013.053065

Santoso, L.W., 2008, 'CRM adoption framework and its success measurement', Proceedings of the International Programme of Action 1999]2000, International Joint Conference in Engineering (IJSE), Jakarta, Indonesia, August 04-05, 2008.

Stefanou, C.J., Sarmaniotis, C. \& Stafyla, A., 2003, 'CRM and customer-centric knowledge management: An empirical research', Business Process Management Journal 9(5), 617-634. http://dx.doi.org/10.1108/14637150310496721

Tassiopoulos, D., 2011, New tourism ventures, 2nd edn., Juta, Cape Town.

Vallabh, D., 2014, 'Customer relationship management in small to medium tourism enterprises (SMTEs) in the Eastern Cape Province', PhD thesis, Department of Business Management, Nelson Mandela Metropolitan University.

Vallabh, D. \& Radder, L., 2010, 'Using CRM as a vehicle to grow small medium tourism enterprises (SMTEs) in a developing economy: Eastern Cape, South Africa. Towards a conceptual framework', paper presented at the 55th International Council for Small Business (ICSB), Cincinnati, Ohio.

Van Aardt, I., Van Aardt, C., Bezuidenhout, S. \& Mumba, M., 2008, Entrepreneurship and new venture management, 3rd edn., Oxford University Press, Cape Town.

Van Schalkwyk, M., 2006, Support for SMMEs key to tourism ASGISA success, Statement by the office of Marthinus van Schalkwyk, Minister of Tourism, South Africa, viewed 18 April 2012, from www.environment.gov.za [URL no longer available].

Yilmaz, B.S., 2008, Competitive advantage strategies for SMES: A case study in tourism sector, presented at MIBES 2008, July 04-05, Larissa, Greece.

Zablah, A.R., Bellenger, D.N. \& Johnston, W.J., 2004, 'An evaluation of divergent perspectives on customer relationship management: Towards a common understanding of an emerging phenomenon', Industrial Marketing Management 33(6), 475-489. http://dx.doi.org/10.1016/j.indmarman.2004.01.006 